Original Article

\title{
Relationships between menopausal syndrome and sleeping of middle-aged women
}

\author{
Yi Kyun Park, RN, MS ${ }^{1)}$, Nam Hyun Cha, RN, PhD'2), Sohyune R. Sok, RN, PhD ${ }^{3)^{*}}$ \\ 1) Department of Nursing, Graduate School, Kyung Hee University, Republic of Korea \\ 2) Department of Nursing, Andong National University, Republic of Korea \\ 3) College of Nursing Science, Kyung Hee University: 26 Kyungheedae-ro, Dongdaemun-gu, Seoul \\ 130-701, Republic of Korea
}

\begin{abstract}
Purpose] This study aimed to examine the correlation between menopausal syndrome and sleep state of middle-aged women, and to examine the factors influencing menopausal syndrome. [Subjects] The subjects included 59 middle-aged women in Seoul, South Korea. [Methods] A cross-sectional design was adopted. The measurement tools were a general characteristics form, Menopause Symptom Index (MENSI), and sleep state scale. [Results] There was a significantly negative correlation between menopausal syndrome and sleep state of middle-aged women. The analyses showed that the prediction model was significant. The value of the adjusted $\mathrm{R}^{2}$ was 0.279 , which corresponds to an explanatory power of $27.9 \%$. The factor found to have the most influence on menopausal syndrome of middle-aged women was sleep state, followed by sexual life satisfaction, and health status. [Conclusion] Nursing intervention programs for alleviating menopausal syndrome of middle-aged women are essential in order to improve sleep state, sexual life satisfaction, and health status. The findings from this study will contribute to help them for controlling and relieving the menopausal syndrome of middle-aged women.

Key words: Menopausal syndrome, Sleep
\end{abstract}

(This article was submitted Mar. 25, 2015, and was accepted May 15, 2015)

\section{INTRODUCTION}

Human life expectancy has been extended, thanks to the developments in technology and medical science, as well as in living standards. The female life expectancy in Korea recently reached 84.5 years ${ }^{1)}$. In an era of longevity, half of the life span is the middle- or old-age period. Middle-aged women usually experience irregular menstruation or complete termination of menstruation between the ages of 40 and 60. Aging symptoms in the physical, emotional, social, and biological aspects start during this age band, which is called the menopausal period ${ }^{2}$. About $38-98 \%$ of Korean women experience menopausal symptoms ${ }^{3)}$ such as flush, cold extremities with sleeping sensation, sweating, vaginal and valvular atrophy, joint pain, and palpitation due to endocrinal imbalance ${ }^{4}$. More than half of women in their menopausal period experience mental and physical symptoms such as palpitation, dizziness, fatigue, and headaches due to autonomous nervous system changes, and to personality and psychological factors ${ }^{5}$. Psychological symptoms observed in $20-50 \%$ of menopausal women include sleep disorder, depression, neurotic symptoms, stress, nervousness, and

*Corresponding author. Sohyune R. Sok (E-mail: 5977sok@ khu.ac.kr)

(C) The Society of Physical Therapy Science. Published by IPEC Inc. This is an open-access article distributed under the terms of the Creative Commons Attribution Non-Commercial No Derivatives (by-ncnd) License $<$ http://creativecommons.org/licenses/by-nc-nd/3.0/> . anxiety $^{6-9)}$.

Physical and hormonal changes in middle-aged women can cause menopausal symptoms and sleep disorders, which may result in deterioration of concentration and judgment ${ }^{5}$. The most common sleep disorder symptom is insomnia accompanied by fatigue and distraction, which develop more frequently in women and the elderly. In particular, 53.6\% of women aged 45-69 experience these symptoms ${ }^{4,5}, 10$ ). Sleep disorder in middle-aged women is caused not only by hormonal deficiency but also by various aging symptom of individuals, lifestyle, sociopsychological factors, and environmental factors ${ }^{11,12)}$. Women with more severe menopausal symptoms experience more severe sleep disorders, and women with sleep disorders have higher levels of depression, stress, and anxiety than women without sleep disorders ${ }^{11,13)}$.

In this study, information on menopausal symptoms and sleep disorders in middle-aged women was described to help them control and relieve such symptoms. To explore effective methods of self-control of middle-aged women pertaining to their health, their menopausal symptoms and sleeping features were investigated, and the correlation of their menopausal symptoms with their sleep disorders was investigated. The aims of the study were: (1) to confirm the general characteristics of subjects, (2) to examine the differences in menopausal syndrome and sleep state according to general characteristics of the subjects, (3) to examine the correlation between menopausal syndrome and sleep state of subjects, and (4) to examine the factors that influence the menopausal syndrome. 


\section{SUBJECTS AND METHODS}

\section{Subjects}

In this study, a cross-sectional design was adopted. The study sample was comprised of middle-aged women in Seoul, South Korea. They were recruited through random sampling using a coin toss. After research approval from the university, the questionnaires were distributed to 63 middleaged women who were willing to participate in this study. The response rate was $93.7 \%$. Due to incomplete data, a total of 59 subjects with complete data were included in the final dataset.

Sample size adequacy $(\mathrm{N}=49)$ using Exact test, $\mathrm{G}$ power 3.1 analysis software was estimated based on an alpha level $=0.05$, medium effect size $=0.35$, and power $=0.8^{14}$. Therefore, the sample size in the study was adequate.

\section{Methods}

The study questionnaire was designed to the measure general characteristics, menopausal syndrome, and sleep state of subjects. General characteristics consisted of significant variables found in a review of previous studies. The variables were age, education, marital state, initial age at menarche, regularity of menstrual period, delivery type, sexual life satisfaction, health status, and drinking. These variables were assessed with a total 9 items. The MENSI (Menopause Symptom Index) developed by Sarrel ${ }^{15)}$ was revised by Han, and it was used to measure the menopausal syndrome among the participants. It consisted of a total of 20 questions using a 3-point scale. The possible score range was 0 to 40 , and the higher the score of the respondent was, the higher their level of menopausal syndrome. Cronbach's alpha reliability coefficient for this instrument was 0.94 . The sleep state scale developed by $\mathrm{Oh}^{16)}$ was used to measure the sleep state among the participants. It consisted of a total of 15 questions using a 4-point scale. The possible score range was 15 to 60 , and the higher the score of the respondent was, the better their level of sleep state. Cronbach's alpha reliability coefficient for this instrument was 0.91 .

The response data were collected by the author and an assistant researcher from March to August 2014. The researcher contacted the prospective participants in Seoul, South Korea, and explained the purpose of this study as well as the participation details and the instruments that were to be used. The survey consisted of a self-reported questionnaire to be administered by the researcher and the assistant. Each of the participants took approximately $15-20 \mathrm{~min}$ to complete the questionnaire.

The collected data were analyzed using the SPSS version 20 statistical software program. General characteristics of the participants were analyzed using descriptive statistics. Differences in menopausal syndrome and sleep state according to general characteristics of the subjects were analyzed using the independent t-test or ANOVA. In order to examine the factors influencing their level of menopausal syndrome, multiple regression analysis was used.

This study was approved by the Institutional Review Board of a University in Seoul, South Korea. In order to obtain consent, a researcher first contacted each individual and explained the purpose, sample criteria, participation details, and instruments of this study. The participants were informed regarding anonymity and confidentiality of data. The researcher received written permission from all participants.

\section{RESULTS}

General characteristics of participants are shown in Table 1. Thirty-four of them (57.6\%) were aged $50-59$, and 18 $(30.5 \%), 40-49 ; 62.7 \%$ had a high school or lower education level, and $37.3 \%$, a college or higher level; and $81.3 \%$ were married. The age of the first menstruation of 33 of the subjects $(55.9 \%)$ was $15-16$, and of 17 of the subjects $(28.9 \%)$, 14 or younger. At the time of the study, $72.8 \%$ of the subjects had completed their menstruation. Natural birth was the subjects' most common (71.2\%) type of delivery. Their sexual life satisfaction level was mainly 'good' $(45.8 \%)$, followed

Table 1. General characteristics and differences in menopausal syndrome and sleep state according to general characteristics of participants $(\mathrm{N}=59)$

\begin{tabular}{|c|c|c|c|c|}
\hline \multicolumn{2}{|c|}{ Characteristics } & $\begin{array}{l}\text { Total } \\
\mathrm{n}(\%)\end{array}$ & $\begin{array}{c}\begin{array}{c}\text { Meno- } \\
\text { pausal } \\
\text { Syndrome }\end{array} \\
\mathrm{M}(\mathrm{SD}) \\
\end{array}$ & $\begin{array}{c}\text { Sleep state } \\
\mathrm{M}(\mathrm{SD}) \\
\end{array}$ \\
\hline \multirow[t]{3}{*}{ Age (yrs) } & $40-49$ & $18(30.5)$ & $18.7(2.1)$ & $37.6(3.4)$ \\
\hline & $50-59$ & $34(57.6)$ & $21.3(1.4)$ & $39.6(3.5)$ \\
\hline & $60-$ & $7(11.9)$ & $18.7(1.9)$ & $41.0(3.8)$ \\
\hline \multirow{3}{*}{ Education } & $\begin{array}{l}\text { High school } \\
\text { or below }\end{array}$ & $37(62.7)$ & $20.5(4.7)$ & $37.6(7.1)$ \\
\hline & $\begin{array}{l}\text { College or } \\
\text { above }\end{array}$ & $22(37.3)$ & $19.6(5.1)$ & $41.7(9.9)$ \\
\hline & Married & $48(81.3)$ & $20.2(3.5)$ & $39.8(3.1)$ \\
\hline \multirow[t]{2}{*}{ Marital state } & Single & $2(3.4)$ & $20.0(3.8)$ & $40.5(6.1)$ \\
\hline & Other & $9(15.3)$ & $20.2(1.8)$ & $35.1(3.1)$ \\
\hline \multirow{3}{*}{$\begin{array}{l}\text { Initial age } \\
\text { at menarche } \\
\text { (yrs) }\end{array}$} & 14 or below & 17 (28.9) & $18.3(1.4)$ & $43.0(2.5)$ \\
\hline & $15-16$ & $33(55.8)$ & $21.2(1.4)$ & $37.7(2.5)$ \\
\hline & 17 or above & $9(15.3)$ & $20.1(1.9)$ & $37.1(3.4)$ \\
\hline \multirow{3}{*}{$\begin{array}{l}\text { Regularity } \\
\text { of menstrual } \\
\text { period }\end{array}$} & Regular & $15(25.4)$ & $18.5(4.7)$ & $37.7(6.7)$ \\
\hline & Irregular & $1(1.7)$ & $18.0(0.0)$ & $31.0(0.0)$ \\
\hline & Both & $43(72.9)$ & $20.8(4.8)$ & $39.8(8.9)$ \\
\hline \multirow{4}{*}{$\begin{array}{l}\text { Delivery } \\
\text { type }\end{array}$} & Natural D. & $42(71.2)$ & $20.2(1.6)$ & $39.6(4.4)$ \\
\hline & C-sac D. & $13(22.0)$ & $20.2(2.8)$ & $36.9(4.9)$ \\
\hline & None & $4(6.8)$ & $20.0(2.8)$ & $41.3(4.4)$ \\
\hline & Satisfy & $12(20.3)$ & $7.6(1.4)^{\mathrm{a}}$ & $45.2(2.7)^{\mathrm{a}}$ \\
\hline \multirow{3}{*}{$\begin{array}{l}\text { Sexual life } \\
\text { satisfaction* }\end{array}$} & Moderate & $27(45.8)$ & $20.4(1.4)$ & $37.8(2.7)^{\mathrm{b}}$ \\
\hline & Dissatisfy & $12(20.4)$ & $22.8(1.7)^{\mathrm{b}}$ & $38.5(3.1)$ \\
\hline & No comment & $8(13.4)$ & $19.3(7.3)$ & $35.5(4.9)$ \\
\hline \multirow{3}{*}{$\begin{array}{l}\text { Health } \\
\text { status* }\end{array}$} & Poor & $12(20.4)$ & $23.1(1.5)^{\mathrm{a}}$ & $32.8(2.6)^{\mathrm{ab}}$ \\
\hline & Moderate & $33(55.8)$ & $20.1(1.5)$ & $39.5(2.6)^{\mathrm{ab}}$ \\
\hline & Good & $14(23.8)$ & $17.8(1.8)^{\mathrm{b}}$ & $43.9(3.0)^{\mathrm{a}}$ \\
\hline \multirow{2}{*}{ Drinking } & Yes & $8(13.6)$ & $20.1(5.5)$ & $38.0(4.3)$ \\
\hline & No & $51(86.4)$ & $20.2(4.8)$ & $39.3(8.9)$ \\
\hline
\end{tabular}

$* p<0.05$

a, b Scheffe post hoc test 
by 'satisfactory' (20.3\%), and 'dissatisfied' (20.4\%). In terms of their health status, $55.8 \%$ said it was 'good'; $23.8 \%$, 'fair'; and 20.4\%, 'bad.' Most (86.4\%) of the subjects were alcohol drinkers (Table 1).

Differences in menopausal syndrome and sleep state according to general characteristics of participants are shown in Table 1. The analysis of the differences in the subjects' menopausal symptoms showed significant differences in their sexual life satisfaction and health status. In the post-hoc comparison, the sexually satisfied subjects showed significantly milder menopausal symptoms than the sexually dissatisfied subjects; and the subjects with a poor health status showed significantly more severe menopausal symptoms than those with a good health status. The analysis of the differences in the subjects' sleep disorders based on their general characteristics showed significant differences according to the sexual life satisfaction and health status. In the post-hoc comparison, the subjects with a satisfactory sexual life had better sleep patterns than those who were dissatisfied with their sexual life, and those with a better health status had better sleep patterns than those with a poorer health status (Table 1).

The middle-aged women's menopausal symptoms showed a significantly negative correlation with their sleeping patterns $(\mathrm{r}=-0.427, \mathrm{p}=0.001)$.

To investigate the influencing factors of middle-aged women's menopausal symptoms, general characteristics variables, which were nominal variables, were transformed into dummy variables, and subjected to multiple regression analysis. The factor that most significantly affected the menopausal symptoms was the sleep state $(\beta=-0.427$, $p=0.001)$, followed by the sexual life satisfaction $(\beta=0.344$, $\mathrm{p}=0.009)$ and the health status $(\beta=-0.333, \mathrm{p}=0.011)$. The explanation ability of these factors was $27.9 \%$.

\section{DISCUSSION}

In this study, menopausal symptoms showed a significantly high correlation with sleeping patterns, sexual life satisfaction, and health status.

Sleeping was the variable that most significantly affected menopausal symptoms. This result corresponded with that of the study of Krystal ${ }^{17}$, in which also the incidence of sleep disorder increased with age, particularly in menopausal women. The results of this study also corresponded with those of the study of Laura et al. ${ }^{18}$, in which the levels of estrogen, progesterone, and norepinephrine decreased with the aging process, and the decrease in the serotonin level led to depression, which affected the subjects' sleeping patterns. The results of this study also corresponded with those of the study of Chung and Tang ${ }^{13)}$, in which the more severe menopausal symptoms resulted in more severe sleep disorders. Sleep disorders cause physical fatigue and poor concentration, and consequently, health problems. Therefore, middle-aged women with sleep disorders show more depression symptoms and higher levels of stress and anxiety than middle-aged women who sleep well ${ }^{11)}$. Considering that sleep disorders can affect quality of life ${ }^{19}$, a method and environment that bring about a good night's sleep must be developed, and support for psychological stability is required.

The comparison of the menopausal symptoms with the sociodemographic features showed that the subjects with a higher sexual life satisfaction level and health status had milder menopausal symptoms. These corresponded with the results of the study of Yeun et al. ${ }^{20}$ ), in which the subjects with more severe menopausal symptoms showed lower sexual life satisfaction. A satisfactory sexual life is a mean of physical relief, which enhances the affinity of the couple through communication that can solve conflicts and eventually improve their quality of life ${ }^{21-25)}$. Thus, information on how to have a satisfactory sexual life and educationally supportive environments are required to improve menopausal symptoms. Moreover, in this study, a good health status was correlated with mild menopausal symptoms, which corresponded with the results of the study of Yeun et al. ${ }^{20)}$, and Chang \& $\mathrm{Lai}^{26)}$. If information to minimize menopausal symptoms and supportive environments are provided to middle-aged women through health education programs, their menopausal symptoms may be relieved and behavioral changes may occur to promote their health status.

In conclusion, in middle-aged women, menopausal symptoms showed a significant correlation with sleeping, sexual life satisfaction, and health status. The variable that most significantly influenced menopausal symptoms was sleep disorder, followed by sexual life satisfaction and health status; and the explanation ability of these variables was $27.9 \%$. To relieve the menopausal symptoms, the proper environment for a good night's sleep, and individual interventions such as sexual life satisfaction and health status improvement, are required. Additionally, health promotion programs and education systems are required at the community level. Further studies on the various factors that can affect the menopausal symptoms of middle-aged women, and on the development of interventions such as a sleeping promotion program may be needed in the future.

The generalizability of this study's results is limited since the participants were recruited from only one metropolitan city in South Korea, which limited the characteristics of the resulting data. Therefore, replication of this study using larger samples drawn from middle-aged women in both the same and different regions of the country is recommended to confirm the generalizability of the results.

\section{ACKNOWLEDGEMENT}

The authors are grateful to all the participants who participated in the study.

\section{REFERENCES}

1) Korea National Statistical Office: Statistics of population in the future Seoul: National Statistical Office, 2013.

2) Rymer J, Morris EP: "Extracts from "Clinical evidence": Menopausal symptoms. BMJ, 2000, 321: 1516-1519. [Medline] [CrossRef]

3) Choi MS: Effects of a program for relieving menopausal symptoms. Unpublished doctoral dissertation, Korea University, Seoul, 2012.

4) Kim HY: Sleep disorders in post menopausal women. J Kor Soc Menopause, 2007, 13: 1-7.

5) Cho SR: Relationship among health belief, hopelessness, quality of sleep and happiness index according to exercise participation of middle-aged 
women Unpublished doctoral dissertation, Dankook University, Yonginsi, Gyeonggi-do, 2012.

6) Shin HS, Yang EY: A study on using of complementary alternative therapies in middle aged women. Proceeding book of The Kor Soc Maternal Child Health, 2010, 28.

7) Kakkar V, Kaur D, Chopra K, et al.: Assessment of the variation in menopausal symptoms with age, education and working/non-working status in north-Indian sub population using menopause rating scale (MRS). Maturitas, 2007, 57: 306-314. [Medline] [CrossRef]

8) Soules MR, Sherman S, Parrott E, et al.: Executive summary: stages of reproductive aging workshop (STRAW). Climacteric, 2001, 4: 267-272. [Medline] [CrossRef]

9) Speroff L: The menopause: A Signal of the Future. Im, R. A, 1994.

10) Sukegawa $T$, Itoga $M$, Seno $H$, et al.: Sleep disturbances and depression in the elderly in Japan. Psychiatry Clin Neurosci, 2003, 57: 265-270. [Medline] [CrossRef]

11) Owens JF, Matthews KA: Sleep disturbance in healthy middle-aged women. Maturitas, 1998, 30: 41-50. [Medline] [CrossRef]

12) Shaver JL, Zenk SN: Sleep disturbance in menopause. J Womens Health Gend Based Med, 2000, 9: 109-118. [Medline] [CrossRef]

13) Chung KF, Tang MK: Subjective sleep disturbance and its correlates in middle-aged Hong Kong Chinese women. Maturitas, 2006, 53: 396-404. [Medline] [CrossRef]

14) Faul F, Erdfelder E, Lang AG, et al.: G*Power 3: a flexible statistical power analysis program for the social, behavioral, and biomedical sciences. Behav Res Methods, 2007, 39: 175-191. [Medline] [CrossRef]

15) Sarrel PM: Evaluation and management of the postmenopausal patients. Female Patient, 1995, 20: 27-32.

16) Oh JJ, Song MS, Kim SM: Development and validation of Korean sleep scale. J Kor Acad Nurs, 1998, 28: 563-572.

17) Krystal AD: Insomnia in women. Clin Cornerstone, 2003, 5: 41-50. [Medline] [CrossRef]

18) Laura AP, Debra JB: Depression in the United States household population. 2005-2006, NCHS data Brief, 2006, 7: 1-8.

19) Son YJ: The influencing factors on health related quality of life (HRQOL) in married working women. Kor J Adult Nurs, 2007, 19: 422-435.

20) Yeun EJ, Kwon YM, Song MS, et al.: Correlational study on health behaviors, menopausal symptoms and sexual satisfaction in Korean middle-aged women. Kor J Adult Nurs, 2004, 16: 502-512.

21) Kim SJ, Kim SY: A study on the relationship of marital intimacy, depression, and menopausal symptoms in middle-aged women. Kor J Women Health Nurs, 2013, 19: 176-187. [CrossRef]

22) Han SH: Study on the menopausal symptoms, menopausal management and quality of life in middle aged women. Unpublished master thesis, Ewha Womans University, Seoul, 2004.

23) Klose M, Jacobi F: Can gender differences in the prevalence of mental disorders be explained by sociodemographic factors? Arch Women Ment Health, 2004, 7: 133-148. [Medline] [CrossRef]

24) Jee Y, Kim Y: Factors influencing sexual function of middle-aged married Korean women. J Phys Ther Sci, 2015, 27: 819-823. [Medline] [CrossRef]

25) Korkmaz N, Tutoğlu A, Korkmaz I, et al.: The relationships among vitamin D level, balance, muscle strength, and quality of life in postmenopausal patients with osteoporosis. J Phys Ther Sci, 2014, 26: 1521-1526. [Medline] [CrossRef]

26) Chang WD, Lai PT: Different exercise behaviors influence heart rate variability, autonomic nerve system function and menopausal symptoms in post-menopausal women. J Phys Ther Sci, 2013, 25: 477-481. [CrossRef] 